\title{
LA PERSONA HUMANA INTEGRALMENTE CONSIDERADA PARA SU EDUCACIÓN.
}

THE HUMAN PERSON INTEGRALLY CONSIDERED FOR ITS EDUCATION.

Patricia lbargüengoitia y Rentería Doctorada en Ciencias Humanas por la Universidad Simón Bolívar y en Psicología Familiar por la International

Christian University, Maestra en Pedagogía por la Facultad de Filosofía y Letras de la UNAM, Psicóloga Social por la UAM-IX., docente del posgrado de la Universidad La Salle Pachuca y del Colegio de Estudios de Posgrado de la Ciudad de México. pibarguengoitia@yahoo.com.mx

\section{Resumen}

En este artículo se define a la persona humana individual, incomunicable e intransferible por su naturaleza creada, así como la importancia de ser considerada con estas características que la integran con sus facultades superiores y su unidad ontológica de cuerpo y alma, así como su naturaleza social a fin de ser tomada en cuenta para proporcionarle una educación integral.

Palabras clave: Facultades cognoscitivas sensitivas, facultades sensitivas afectivas, facultades racionales: intelecto y voluntad.

\section{Abstract}

This article defines the individual human person, incommunicable and non-transferable by its created 
nature, as well as by the importance of being considered with these characteristics which integrate it with its higher faculties and its ontological unity of body and soul, as well as its social nature in order to be taken into account to provide it with an integral education.

Key words: Cognitive sensitive faculties, sensitive affective faculties, rational faculties: intellect and will.

\section{Introducción}

\section{Dimensión personal del hombre}

El objeto de la educación, es el perfeccionamiento de la persona humana y por lo tanto lo primero que hay que tener claro es su naturaleza. Para ello hay que recurrir al ser (Ocampo, 2002:54), pues sólo así tendremos un conocimiento objetivo y profundo de la persona humana. De ahí que tengamos que penetrar en su conocimiento con el rigor metafísico necesario para evitar confusiones en las disciplinas sociales como son en primer lugar la educación, así como en diversas áreas como el derecho, la economía, la política y otras.

La persona es "sustancia individual de naturaleza racional" definición de Boecio aceptada por Santo Tomás (2001: I pars, q. 29, a. 7). La sustancia de suyo excluye los accidentes y con la naturaleza racional excluye a los seres puramente materiales. Esta definición puede aplicarse analógicamente tanto a la persona humana como a la angélica y a Dios. Así que el hombre siendo material y a la vez racional se distingue de los seres puramente materiales e irracionales como las plantas y 
las bestias, así como de los seres racionales inmateriales como son los ángeles y Dios mismo, con sus tres Divinas Personas. El hombre por tanto como persona, está comprendida en la definición de Boecio y además posee alma y cuerpo. Ninguno de las dos instancias por separado comprende el concepto de persona humana.

La persona humana creada incluye el ser (ente), la esencia y el "esse" o acto de ser y significa una cierta naturaleza y un cierto modo de existir que es la subsistencia "... y por lo tanto, su constitutivo propio formal es el esse propio aunque participado..." de Dios, "... que es su causa." (Ocampo, 2002:48) Es común en nuestra época observar en las actitudes de las personas, cómo evaden esta realidad ontológica, haciendo mucho ruido, oyendo música estridente, que no es música, corriendo de aquí para allá, complicándose la vida y echándose encima cargas absurdas de una manera tan liviana, y todo ello por causa de una educación errónea.

En todos los casos, la persona es una individualidad intransferible que expresa su unidad interna, distinta de los demás, en la medida en la que sea una, incomunicable por el mismo acto de existir otorgado a la persona por el esse. Este esse incomunica y completa a la persona una y distinta a la vez, y es común a las demás por aquello por lo cual es una y distinta (Ocampo, 2002:49). La incomunicabilidad ontológica es, fundamento de la comunicación personal e interpersonal.

La persona humana puede comunicarse con sí misma, con el otro y con Dios a partir de su unidad ontológica de cuerpo y alma. Por medio de la educación el hombre 
desarrolla la totalidad de esta unidad ontológica, cumpliendo así con su destino y su naturaleza social y su relación con Dios, de acuerdo a la teodicea, que estudia a Dios a la luz natural de la razón. Esta unidad de cuerpo y espíritu, es incomunicable al otro, y sólo descubriéndola cada quien, la relación y comunicación auténtica con el otro y con Dios, podrá consumarse. Vemos así cómo el principio próximo de las operaciones, son las potencias operativas, siendo el alma espiritual el principio remoto de las potencias operativas. Si se aplica la acción de hacer emerger, educir, -significado de la verdadera educacióntodo lo que el hombre es y sus potencias, desde su concepción, que ya posee la persona humana, entonces es cuando se puede hablar de una verdadera educación; este dar a luz en la educación, es con la enseñanza de la disciplina en la práctica de las virtudes, tanto intelectuales como morales. Sólo así, el hombre puede llegar a su máxima perfección posible.

Lo anterior implica que la persona humana al estar creada con una espiritualidad con facultades superiores, ha de relacionarse con esa herencia que le viene dada de Dios, persona Divina perfectísima, la cual se descubre sólo a la luz natural de la razón y de la contemplación. Esta acción de interiorización, es la acción que hace que el hombre conozca su naturaleza espiritual trascendente y sólo con la guía de una buena educación se puede lograr. Esto es lo que constituye la apertura hacia Dios, y sin ella no es posible la apertura auténtica a sí mismo ni a Dios. Negar alguna de estas dimensiones, es negar las otras, pues la persona humana integrada incluye el yo, el otro y Dios. Integralmente, el hombre es destruido al negar alguna de ellas. Las corrientes actuales en educación, sólo 
consideran al hombre como ser social, o un ser con lenguaje con el cual piensa y construye conocimiento, o también un cuerpo que debe ser productivo, lo cual lleva al hombre hacia su propia destrucción por no ser perfeccionado en su crecimiento a través de la buena educación en la práctica de las virtudes y en la consideración ontológica de la persona humana, en su unidad inherente de cuerpo y alma.

Siendo la persona humana una unidad, no hay sólo un acto de esta unidad que no incluya el todo, y el todo está implicado a su vez en cada uno de sus actos. El esse es lo más íntimo, lo más profundo del ente, es acto primero que posibilita los otros actos.

El término sustancia según la Metafísica se refiere tanto a la esencia sustancial universal o sustancia segunda; como a la esencia sustancial singular o esencia individualizada llamada sustancia primera. También la sustancia significa lo que subsiste o esencia sustancial que subsiste, en el momento en que no es abstracta sino una realidad concreta. La sustancia es así aquello que existe en sí mismo y no en otro como los accidentes. No todas las sustancias son subsistentes, y la causa de la subsistencia es el ser proporcionado a la esencia.

Las cualidades, como accidentes del ser sustancial son de cuatro especies: hábito y disposición, potencia e impotencia, pasión y cualidad pasible, forma y figura. Así, como la educación dispone a la persona humana al bien y le desarrolla hábitos buenos, es decir virtudes, tenemos la primera de las cuatro especies de accidente cualidad que se refiere al hábito disposición. Si dispone al hombre a la 
actividad o acción, la educación en la segunda especie referida a la potencia e impotencia. La tercera especie, pasión y cualidad pasible se aplican al considerar a la educación un efecto recibido por el hombre educado. Y la cuarta especia correspondiente a la forma y figura, se refiere a la determinación cuantitativa que dispone a la naturaleza humana en su entidad corporal. Pues sabemos la armonía que se da en este aspecto en una persona humana bien educada.

Como la persona es la esencia sustancial individual que subsiste, que posee el existir en sí y por sí, posee un ser propio. La persona expresa lo subsistente en la esencia de la naturaleza, es decir, el ente subsistente. Por lo tanto, la expresión sustancia individual significa la sustancia íntegra y completa desde el orden entitativo. (Tomás de Aquino, 2001: III pars, q. 16, a. 12, ob. et ad. 1)

Santo Tomás identifica la existencia como un efecto del esse $o$ actus essendi quien hace que el ente exista y convierte a la esencia en ente. El existir in se et per se es el esse que al existir en sí es algo esencial y subsistente gracias al esse. (Ocampo, 2002:50)

Si se considera a la persona creada en su acepción esencial, el esse es un constitutivo extrínseco, y es intrínseco si se considera a la persona creada en su acepción formal (o sea real) pues se trata de sus constitutivos ontológicos: esencia o naturaleza y esse. (Ocampo, 2002:54)

\section{Dimensiones operativas de la persona humana}


Una vez vista la dimensión personal del hombre es necesario apuntar hacia sus principios operativos y considerarlo en su aspecto dinámico. Con tal aspecto nos referimos a sus facultades. Éstas son los principios operativos próximos de los seres vivos.

La potencia y el acto dividen a cualquier ser, por lo cual es necesario que ambos estén referidos al mismo género. El alma del hombre donde radican las facultades intelectiva y volitiva está en acto. En acto primero en cuanto subyace a su potencia, pero el ser dotado de alma no siempre está llevando a cabo acciones vitales. La esencia de alma no es su potencia, pues nada está en potencia con respecto a un acto en cuanto que es acto. (Tomás de Aquino 2001: I pars, q. 77, a. 1, sol.)

En el alma humana, por otra parte, hay muchas potencias y por lo tanto, al realizar sus operaciones a través de sus potencias, puede alcanzar la perfecta y universal bondad y la bienaventuranza, en cuanto se refieren a su felicidad. Ya que el alma humana se encuentra en el límite entre los seres espirituales y corporales, en ella concurren tanto las potencias de unas como de las otras. (Tomás de Aquino, 2001: I pars, a. 2., sol.)

Por otro lado, la potencia ordenada al acto, es necesario que esté determinada por el acto al que está ordenada, y toda acción responde o a una potencia activa o a una potencia pasiva. Respecto del acto de una potencia pasiva, el objeto es como principio y causa motora. (Tomás de Aquino, 2001: I pars, q. 27, a. 3, sol.) Es necesario asimismo, que haya orden entre las potencias. 
Dos órdenes provienen de la dependencia entre las potencias, y otro orden proviene de los objetos. El orden dependiente de las potencias proviene por un lado, de la naturaleza perfecta y por otro de la generación y del tiempo. (Tomás de Aquino, 2001: I pars, q. 77, a. 4, sol.) En el orden que proviene de los objetos, es necesario también que la potencia pertenezca como sujeto a quien realiza la operación, y tales potencias, principio de tales operaciones, están en el propio sujeto y no sólo en el alma.

A su vez, tanto la forma sustancial como la accidental son actos, no obstante se diferencian en que la forma sustancial es el esse que junto con la materia y el sujeto de la forma accidental es el ser en acto; es decir, la forma sustancial es la causa de que su sujeto esté en acto; así el sujeto en cuanto que está en potencia, recibe la forma accidental.

La forma sustancial y la accidental también se diferencian en que, como sea que lo menos principal existe por lo más principal, la materia existe por razón de la forma sustancial. Asimismo la forma accidental se da para completar al sujeto. (Tomás de Aquino, 2001: I pars, q. 77 , a. 6 , sol.)

En este orden, una potencia del alma procede de la esencia del alma a través de otra potencia. Así aquellas potencias del alma, las primeras según su orden y perfección, son a su vez el origen de las demás en cuanto fin y principio eficiente. Aunque las más imperfectas son anteriores en el proceso de generación. (Tomás de Aquino, 2001: I pars, q. 77, a. 7, sol.) 
Ahora bien, las potencias del alma en especial son intelectivas y sensitivas. Las potencias que preceden al entendimiento son las potencias vegetativas, los sentidos externos y los sentidos internos. (Tomás de Aquino, 2001: I pars, q. 78, introducción) Cada una de las potencias tienen sentido al desear el objeto que les es propio. (Tomás de Aquino, 2001: I pars, q. 78, a. 1, objeciones) En "De Anima" Aristóteles llama potencias a las facultades vegetativa, sensitiva, apetitiva, locomotriz e intelectiva. (Tomás de Aquino, 2001: I pars, q. 78, a.1, objeciones) Cada una de ellas se distingue por su objeto. Cuanto más noble es una potencia, más universal es el objeto sobre el que actúa. Las potencias sensitivas se refieren al objeto del cuerpo sensible, esto es el objeto menos común; en cambio las potencias intelectivas se refieren al objeto más universal. Las potencias apetitivas que tienden al objeto exterior, tienden al objeto en el orden de la intención, y las locomotrices tienden al término de su operación y movimiento. Hasta aquí, estoy tratando las necesidades de los animales irracionales. Otros vivientes tienen además de éstas, la inteligencia y la voluntad, como son los hombres. (Tomás de Aquino, 2001: I pars, q. 78, a. 1, sol.) Es en ellas en las que intervienen la educación en cuanto que depende de los conocimientos adquiridos que la voluntad se inclina a determinadas acciones.

Por otra parte, conocer la naturaleza de las cualidades sensibles, es propio del entendimiento. El tacto y el gusto, son los sentidos externos más materiales. En cambio la vista, el oído y el olfato son sentidos externos que trastocan el intelecto y la voluntad, es decir, las facultades del alma. 
Los sentidos internos hacen tener una estimación sobre los objetos percibidos por los sentidos externos. La imaginación o fantasía capta los objetos, la facultad estimativa o cogitativa en el hombre, distingue de lo percibido entre lo bueno y lo malo y la memoria retiene, es decir, conserva las intenciones de la voluntad, (Tomás de Aquino, 2001: I pars, q.78, a. 4).

\section{Facultades del hombre}

Ha quedado expuesto que el hombre es una unidad substancial de cuerpo y alma que además se perfecciona gracias a sus cualidades accidentales entre las que se encuentran las facultades. Por esta razón profundizaré en las facultades o principios operativos, los cuales están representados por el aspecto dinámico de la persona humana educada y perfeccionada. El hombre tiene facultades vegetativas y sensitivas al igual que otros seres corpóreos inferiores a él. En cambio, las facultades racionales sólo las posee el hombre.

Las facultades vegetativas de todos los seres vivos corpóreos se refieren a la nutrición, el crecimiento y la reproducción.

Las facultades sensitivas que son comunes al hombre y al animal irracional, pertenecen al orden del conocimiento por medio de los sentidos externos $o$ al orden del afecto que es el apetito sensible.

La potencia locomotiva es la capacidad que tienen los animales para trasladarse $y$ no requiere ni de conocimiento ni de afecto por lo que podemos observar 
que el hombre guiado por el sólo deseo o necesidad de locomoción o del apetito sensible, se está comportando como un ser irracional, de ahí la importancia y trascendencia de la educación verdadera de la persona humana, ya que su objeto es llevarla hacia su máxima perfección que es la felicidad, su fin último.

\subsection{Facultades cognoscitivas sensitivas}

Las facultades cognoscitivas sensitivas permiten al hombre conocer aquello que conviene para su perfeccionamiento al cual tiende la voluntad; por lo tanto, depende del conocimiento presentado a estas facultades, que la persona tienda y decida voluntariamente al objeto presentado para su conocimiento. En el hombre el entendimiento es una potencia del alma y no su misma esencia. La proporción entre potencia y operación es la misma que hay entre esencia y ser. (Tomás de Aquino, 2001: I pars, q. 79, a. 1, sol.) Lo anterior significa que es a través de la educación en hábitos buenos o virtudes que el hombre lleva a cabo en acto las capacidades que tiene en potencia con estabilidad y orden al bien.

Cuando un sujeto es privado de algo que le compete a su naturaleza o su tendencia, se dice padecer. Asimismo cuando al sujeto se le quita algo, tanto si le es, como si no le es debido. Por padecer se entiende también el hecho de que un ser en potencia para algo adquiera aquello para lo que estaba en potencia, aún sin perder nada propio. Así todo ser que pasa de la potencia al acto, puede llamarse paciente, ya que en este sentido nuestro entendimiento es pasivo. Así nuestro entendimiento es un cierto padecer, según el sentido de pasión y por eso el entendimiento 
humano es una potencia pasiva. (Tomás de Aquino, 2001: I pars, a. 2, sol.) Sin embargo, en el entendimiento hay una facultad agente que hace a las cosas inteligibles, en acto, abstrayendo las especies de sus condiciones en acto. (Tomás de Aquino, 2001: I pars, a. 3, sol.).

El entendimiento agente es algo propio del alma, la cual, aunque no llega a entender toda la realidad, sí llega al conocimiento de la verdad mediante la argumentación, el discurso y el movimiento, los cuales deben ser guiados y enseñados por la buena educación. Por eso el alma humana es llamada intelectiva por participar de la facultad intelectual, en ella hay una capacidad operativa proporcionada por el entendimiento superior, por lo que es necesario que esta capacidad, principio de la acción intelectiva, sea algo propio del alma. (Tomás de Aquino, 2001: I pars, q. 79, a. a, sol.) De no ser así, el entendimiento agente sería el mismo en todos los hombres; así que habría tantos entendimientos, como almas. (Tomás de Aquino, 2001: I pars, a. 5, sol.) Lo entendido en acto, a su vez, se archiva en la parte intelectiva. El intelecto se va incrementando con cada una de las cosas en cuanto que recibe las especies de cada uno de los objetos a través de sus aprendizajes adquiridos en la educación. El entender, aunque está en potencia, es acto en tanto que hay la intención de entender. (Tomás de Aquino, 2001: I pars, a.6, sol.) Al archivar lo entendido pasa a la memoria y como tal, esta facultad forma parte de la potencia intelectiva, ya que recibir y conservar las especies de los objetos son actos propios del entendimiento. (Tomás de Aquino, 2001: I pars, a. 7, sol.) Razonar, por otra parte, es el movimiento 
del entendimiento, y ambos son una misma potencia. (Tomás de Aquino, 2001: I pars, a. 8, sol.)

Asimismo existen los primeros principios indemostrables por ser evidentes que forman parte del hábito de entendimiento; las conclusiones que se deducen del mismo, pertenecen al hábito de la ciencia. (Tomás de Aquino, 2001: I pars, a. 9., sol.) Así mientras el intelecto agente es acto, el entendimiento posible es potencia respecto de los inteligibles en cuanto no los conoce.

Ahora bien, el entendimiento práctico y el especulativo no son potencias diversas. Por su parte el entendimiento especulativo no ordena a la acción lo que percibe, sino a la consideración de la verdad y el entendimiento práctico a su vez ordena a la acción lo aprehendido. Aristóteles en "De Anima" explica que el entendimiento especulativo "difiere del práctico en el fin" (Tomás de Aquino, 2001: I pars, a. 11, sol.), ya que el conocimiento práctico es operativo.

Por su parte la sindéresis es un hábito, y no una potencia. Es un hábito especial, natural en nosotros que consiste en reconocer los primeros principios morales. La sindéresis impulsa al bien y censura el mal. Por ella procedemos a la investigación y por ella juzgamos y aunque sea natural su conocimiento, debe ser clarificado en la educación debido a la confusión que ha provocado en nuestra época la información falsa proporcionada por la incorrecta educación. Asimismo la conciencia no es una potencia, sino un acto. Equivale a consaber. "Acusa, excusa y remuerde, es decir, responde a la aplicación del 
conocimiento a lo que hacemos." (Tomás de Aquino, 2001: I pars, q. 79 , a. 13 , sol.)

A las facultades cognoscitivas pertenecen cinco sentidos externos y cuatro internos.

Los sentidos externos son: vista, oído, olfato, gusto y tacto. Responden a estímulos sensibles con la sensación la cual tiene cuatro limitantes: a) es exclusiva para cada sentido; b) es efímera; c) se circunscribe al presente; d) no capta lo útil o trascendental para la persona humana. También los poseen los seres irracionales. (García Alonso, 2000:14)

Los sentidos internos son: el sentido común cuya función es unir o distinguir sensaciones provenientes de diversos sentidos a un mismo objeto o distinguir una misma sensación atribuyéndola a dos objetos diferentes; la imaginación cuya función es darle permanencia a una sensación. Este sentido permite conservar sensaciones y compararlas; la memoria, cuya función es determinar el momento en el que se produjo una imagen; y por último la capacidad estimativa o cogitativa, cuya función es detectar lo útil o lo nocivo para la naturaleza del ser. Representa el instinto de conservación. (García Alonso, 2000:15)

\subsection{Facultades afectivas sensitivas}

Una vez expuestas las facultades cognoscitivas proporcionadas por los sentidos tanto externos como internos, explicaré el tema de las facultades afectivas, las cuales se relacionan con la facultad espiritual de la 
voluntad, cuyo fortalecimiento a través de la educación es conveniente para cumplir con el fin último del hombre que es, como quedó dicho, la felicidad.

Los afectos dependen del conocimiento, y por lo tanto, son posteriores a él. Las facultades afectivas sensitivas son el apetito concupiscible y el apetito irascible. Los apetitos tanto irascible como concupiscible, al representar los deseos de la persona humana, producen en ella pasiones, las cuales según Jolivet (1984:137) corresponden al "...término relativo de la acción, es decir, el hecho de recibir (o padecer) la acción" en su primera acepción. Para García López tanto las emociones como las pasiones son consideradas todas como pasiones ya que las diferencias que hace de ellas la psicología moderna, son diferencias de grado y no de especie. (García López, 1986:325) En todo caso se trata de movimientos del apetito sensible de acercamiento o alejamiento, ya se trate de bienes o de males sensibles respectivamente.

Las pasiones del apetito concupiscible se refieren al bien o al mal sensible fácil de alcanzar y las del apetito irascible al bien sensible, difícil de alcanzar, o al mal sensible difícil de evitar, como dije anteriormente. El mal que es difícil de evitar es doblemente porque es mal por sí y mal por la dificultad que representa evitarlo. "Concupiscere" en latín significa "desear". El apetito concupiscible es la facultad sensitivo-afectiva cuyo objeto es desear el bien o el mal que se presenta de manera fácil. En general, el deseo del bien genera la pasión del amor, y el deseo del mal genera la pasión del odio. Cuando el bien está ausente se genera la pasión del odio 
y cuando el mal está ausente, la pasión que se presenta es la aversión. Por el contrario, cuando el bien está presente, aparece la pasión de la alegría, y cuando el mal está presente, se da la pasión de la tristeza. Aunque la pasión principal que genera a todas las demás, incluyendo las del apetito irascible, es el amor, pues de ella nacen los deseos, ya sean para el bien o para el mal. (García Alonso, 2000:15)

Por otra parte, la facultad sensitiva-afectiva, cuyo objeto es difícil de obtener, ya sea el bien o el mal, es la facultad del apetito irascible. El producto de esta facultad son las pasiones del irascible. Cuando el bien deseado es difícil de conseguir pero asequible, se genera la pasión de la esperanza; si no es asequible, se genera la pasión de la desesperanza. Cuando el mal ausente, difícil de evitar es superable, se produce la pasión de la audacia. De no ser así, se genera la pasión del miedo. Cuando el mal está presente y es difícil de desechar, se genera la pasión de la ira. El bien presente, por supuesto, nunca se desea desechar. En la sociedad actual de muchos países se pueden identificar estas pasiones por las condiciones de pobreza generados por los sistemas económicos liberales internacionales. (García Alonso, 2000:16)

García López (1986:325-325) dice que los psicólogos experimentales hacen una distinción entre pasiones y emociones: las pasiones son movimientos permanentes, a modo de hábitos o disposiciones estables y equivalen a los vicios de los autores antiguos; en cambio las emociones son movimientos súbitos y transitorios, unas veces pasivos y otras, activos, en cuyo caso se llaman sentimientos. 
Según García López, (1986:326) las pasiones del apetito concupiscible son: el amor y el odio, el deseo y la aversión, y la alegría y la tristeza. Para esta división se siguen los siguientes criterios: primero, las pasiones que tienen por objeto el bien sensible son diferentes de las que tienen por objeto el mal sensible; segundo, el bien y el mal sensibles pueden presentarse de tres maneras que dan lugar a otras pasiones: a) en sí mismos, b) en cuanto ausentes, y c) en cuanto presentes. Junto con los dos criterios mencionados tendremos las seis pasiones ya señaladas (amor, odio, deseo, aversión, alegría, tristeza). El bien a sí mismo considerado da lugar a la pasión del amor; el mal sensible ausente, la pasión de la aversión; el bien sensible presente da lugar a la pasión de la alegría y el mal sensible presente, la pasión de la tristeza.

Por otra parte, las pasiones del apetito irascible son: la esperanza y la desesperación, el temor y la audacia y por último la ira. Los criterios para esta división comprenden por un lado el bien y el mal difíciles que provocan estas pasiones y por otro, la superación de la dificultad que subyace en la consecución del bien y en la evitación del mal. Así, un bien difícil de alcanzar, mientras más nos acercamos a él al ir superando los obstáculos, se produce la pasión de la esperanza; el mismo bien difícil, pero imposible de alcanzar, hace alejase de él por la imposibilidad de superar los obstáculos, provoca la pasión de la desesperanza o desesperación. En cambio con el mal difícil de evitar y venciendo los obstáculos que se presentan, nace la pasión de la audacia; y por el contrario la del temor cuando ante el mismo mal difícil de evitar, nos es imposible lograrlo por no vencer los obstáculos 
que se presentan. $Y$ finalmente, ante el mal difícil de evitar, que llega a implantarse, provoca la pasión de la ira. Esta pasión no tiene contrario porque si al fin se logra alcanzar, aunque difícilmente, se da lugar a la alegría que es pasión del apetito concupiscible. (García López, 1986:328) A este respecto, los psicólogos han explicado que el enojo o inconformidad, prolongado el tiempo suficiente con alguna situación en la vida, se convierte en amargura, rasgo que se manifiesta en depresión que obstaculiza el desarrollo de las potencias de la persona humana. Estos conceptos se relacionan con el perfeccionamiento de la voluntad, pues la desesperación, el temor y la ira son consecuencia de una falta de conocimiento del alumno, y comprensión al mismo por parte del maestro al no guiar con amor de acuerdo a las potencias del educando en cuanto a su edad, nivel y condición.

En cuanto al apetito irascible, la primera de las pasiones es la esperanza. Se refiere a un bien sensible ausente difícil de conseguir, pero posible o asequible. Requiere esfuerzo y la posibilidad de alcanzarlo fija y dirige al apetito. En el orden intelectual en sentido analógico se concibe como una intención especialmente intensa de la voluntad, para lo cual se requiere su perfeccionamiento a través de la educación. Las causas que aumentan la esperanza son: la energía tanto física como psicológica; la experiencia de éxitos anteriores y el compañerismo de los amigos y del maestro. Otra causa accidental de la esperanza puede ser la ignorancia de los obstáculos que hay que vencer, lo cual se resuelve con una educación realista fundada en la búsqueda de la verdad, que se da en la educación verdadera, que corresponde a la 
educación en virtudes. Entre los efectos de la esperanza está el aumento del amor, pues más se ama lo que más cuesta. (García López, 1986:338) La desesperación o desesperanza, es la pasión opuesta a la esperanza. Se refiere al bien sensible, futuro, pero inalcanzable. La conciencia de lo inasequible es lo que provoca el movimiento de la desesperanza. En sentido analógico, la desesperación también se encuentra en el orden intelectual. (García López, 1986:339) Entonces, al estar en el orden intelectivo, tanto la esperanza como la desesperanza, son movidas por la voluntad. (Tomás de Aquino, 2001: II-II pars (a), q. 18, a. 1., Sol.)

Las causas de la desesperanza son: la falta de energía física o psicológica, la falta de ayuda de los amigos o la experiencia de anteriores fracasos y también los malos maestros. Los efectos de la desesperanza son: el odio a personas que pueden ayudar y no lo hacen o al mismo bien que es el objeto de la desesperanza. (García López, 1986:335) El odio por su parte, es causado por la envidia, provocada por el bien del otro. (Tomás de Aquino, 2001: II-II pars (a), q. 34, a. 6. Sol.).

El amor por su parte, en sentido propio y analógico se halla en el orden sensible y en el intelectual. El amor como pasión es movimiento del apetito concupiscible. Se provoca por cualquier bien sensible considerado en sí mismo, ya sea que se encuentre ausente o poseído, su causa principal es el propio bien sensible sobre el que versa. Como condición sine qua non es el conocimiento de ese bien, proporcionado por el sentido interno de la imaginación. (García López, 1986:334) El amor se considera la primera de las pasiones tanto del apetito 
concupiscible como del irascible y por eso las otras pasiones se originan en él. Pues se desea lo que se ama y se odia lo que es contrario al objeto del amor; además no se tiene aversión a lo amado sino a la ausencia del bien que se ama. Lo mismo cabe decir de las pasiones del apetito irascible.

El odio, pasión opuesta al amor, radica en el apetito concupiscible. Su objeto es un mal sensible en sí mismo considerado. En sentido analógico, el odio puede encontrarse, como el amor, en el orden intelectual: abominación si se trata de una cosa que se estima mala o nociva y enemistad que versa sobre una persona considerada perversa o enemiga. (García López, 1986:335) Pues en el perfeccionamiento de la persona a través de la educación, se debe enseñar también sobre las cosas o las personas inconvenientes para el propio desarrollo, así como también que el amor puede crecer más y más. (García López, 1986:332)

El deseo es el nombre que designa primeramente el movimiento del apetito concupiscible que tiene por objeto un bien sensible considerado como ausente. Es intermedio entre el amor y el gozo, pues el amor es la primera inmutación pasiva del apetito por lo apetecible y el gozo la última inmutación del apetito por lo apetecible. Tanto el amor como el gozo son extremos a modo de comienzo o a modo de consumación respectivamente. Al deseo en el orden intelectual se le conoce con el nombre de intención. (García López, 1986:335) El deseo en el orden sensible se divide en natural y no natural. El deseo natural versa sobre los bienes sensibles imprescindibles para la vida; el deseo no natural versa sobre los bienes 
sensibles superfluos para la vida. El deseo natural es finito y saciable en acto y el deseo no natural es infinito e insaciable tanto en acto como en potencia. (García López, 1986:336) La persona bien educada en este tema, analiza y toma decisiones individuales o sociales, según sea su posición, adecuadas para su felicidad o el bien común, que es el bien para todos los miembros de una sociedad.

La aversión es pasión opuesta al deseo y versa sobre un mal sensible en tanto que está ausente; es intermedia entre el odio y la tristeza. En sentido analógico también se da en el orden intelectual, y en este caso se habla de detestación. (García López, 1986: 336) El gozo o alegría es la pasión que versa sobre un bien sensible en tanto que está presente o poseído. La fruición es el nombre del gozo intelectual en sentido analógico. (García López, 1986:337) Santo Tomás nos explica sobre el gozo cuando no queda nada por desear. (Tomás de Aquino, 2001: II-II (a) pars, q. 28, a. 3, sol.) La tristeza es la pasión opuesta al gozo. Se tiene cuando se está en presencia de un mal sensible. También se llama pena, aflicción, pesadumbre, dolor, congoja, mesticia, amargura, etcétera. Analógicamente también se halla en el orden intelectual. La tristeza, contraria al gozo, se da en el orden psicológico y fisiológico ya sea que se trate de un dolor interno referido sobre todo a los sentidos internos, o de un dolor corporal. (García López, 1986:337) Contrario a la tristeza es el gozo, ambos proceden del amor. El gozo es, ya sea por la presencia del bien amado o porque el bien amado posee el bien que le corresponde. Por el contrario, la tristeza que nace del amor es por la ausencia del bien amado o porque quien queremos está privado de su bien propio o sufre algún mal. (Tomás de Aquino, 2001: II-II (a) 
pars, q. 28, a. 1., sol.) Con una realidad relativa como la que se maneja en la actualidad, resulta fundamental para el desarrollo de la voluntad, identificar los conceptos que se han explicado en las ciencias del comportamiento humano y que confunden los accidentes con lo sustantivo del ser humano y su existencia.

El temor es la pasión del apetito irascible que tiene por objeto un mal sensible futuro a pesar de la resistencia que se le opone. El temor consiste en la pasión resultante de la inminencia del mal futuro, aunque difícil de evitar. Al estar presente el mal se da lugar a la ira. Analógicamente el temor también puede aplicarse al orden intelectual. (García López, 1986:339) El temor puede ser natural o instintivo y no natural. El primero es el que versa sobre los males que hacen imposible la vida humana; el no natural versa sobre los males que dificultan la vida humana. El temor del mal destructivo es el que la naturaleza rehúye por el deseo natural de existir; en cambio, el temor no natural no repugna a la naturaleza, sino al deseo del apetito. (Tomás de Aquino, 2001: I-II pars, q. 41, a. 3, sol.) Las causas del temor son dos: objetiva que es el mal mismo que amenaza, y subjetiva, que consiste en las disposiciones del sujeto frente al mal. Las subjetivas a su vez son dos: el amor que se tiene al mal que se teme y la debilidad que se tiene para luchar contra ese mal. Los efectos del temor son: primero, el encogimiento de ánimo; segundo, la cogitación que se tiene por buscar los medios para evitar el mal; tercero, el temblor corporal; y cuarto, la paralización, (García López, 1986:339) esto último relacionado directamente con características personales como el funcionamiento orgánico. El maestro eficaz ha de tener conocimiento de estos rasgos en su alumno para 
enseñarlo a manejarlos a través del perfeccionamiento de la voluntad.

La audacia es la pasión del apetito irascible contraria al temor. Tiene por objeto un mal sensible futuro, difícil de evitar. Se trata de "... Un movimiento pasional que se dirige al mal para combatirlo... y va unido a la esperanza de la victoria". (García López, 1986:339) En sentido analógico en el orden intelectual, la audacia consiste en el arrojo de la voluntad para atacar los males y vencerlos. Las causas de la audacia son las mismas que las de la esperanza: la energía física y psicológica, la experiencia de haber superado obstáculos anteriores y el apoyo de los amigos. Indirectamente la ignorancia de los obstáculos a superar es una causa. De aquí que muchos ignorantes busquen la francachela para pasar la vida mejor y fácilmente, actitud que hace caer en los vicios (García López, 1986:341) o hábitos malos contrarios a la virtud, resultado de una voluntad deteriorada por la mala educación.

Luego entonces, en el alma habría potencias apetitivas, pues al igual que las formas de los seres con potencia cognoscitiva son superiores al de las formas naturales, también en ellos se da una tendencia superior y se llama apetito racional. Tal tendencia le corresponde a la tendencia apetitiva del alma, por lo que el animal o la persona humana, pueden apetecer todo aquello que aprehenden y no sólo aquello a lo que les impulsa su forma natural. (Tomás de Aquino, 2001: I pars, q. 80, a. 1, sol.) 
A su vez los objetos conocidos por el entendimiento, son distintos a los objetos entendidos por los sentidos, por lo que el apetito intelectivo propio de la persona humana es una potencia distinta del apetito sensitivo. En este sentido, y hablando de nuestro tiempo, estructurar la educación oficial de acuerdo al bien natural al cual tiende el hombre, conforme a la realidad, lo cual es la verdad, que a su vez conviene para el logro del fin último del hombre, sería muy conveniente tomarlo en cuenta en los planes y programas de estudio.

Para que el hombre pueda llegar a la felicidad, su fin último, la fruición y el gozo, es necesario el conocimiento correcto de la realidad sobre el bien y el mal y sus efectos así como el fortalecimiento de la voluntad y este objetivo lo cumple una buena educación.

\subsection{Facultades espirituales: intelecto y voluntad}

Caturelli (1982:9) nos hace reflexionar sobre la máxima de los antiguos griegos "conócete a tí mismo" a través de Eutidemo, quien estaba convencido de que para ser educado no era necesaria la guianza de un maestro. Si la persona humana no entiende quién es ella misma y no reconoce que no sabe, no puede tener jamás la actitud correcta para aprender. Según Eutidemo, él era autodidacta y al fin acepta que es bastante imbécil, pues no sabe nada, y aún los esclavos saben más que él, pues conocen sus propios oficios como la peletería, la orfebrería, etcétera. El reconocimiento de la ignorancia, tampoco es sabiduría ni humildad, pues es necesario ponerse a estudiar una vez que se ha aceptado ese no saber. Hoy en día, con sólo dar la razón al que sabe ya es 
suficiente, lo cual nos ha llevado a un estado de imbecilidad social, no se conoce la realidad, es decir, la verdad y se vive en un estado de mentira y hasta de esquizofrenia o psicopatía social.

Al no conocer nada de sí mismo, es imposible que la persona humana pueda perfeccionarse. Como se trata del sí mismo, es importante considerar un supuesto metafísico antropológico antes de toda reflexión sobre la educación. El acto de existir equivale a decir que el hombre tiene ante todo, conciencia del ser. Esa autoconciencia o evidencia del ser o esse, es el primer grado de conocimiento de sí mismo. (Caturelli, 1982:14) El único "ente" que tiene conciencia de este acto primero, es el hombre, en quien esta primera aprehensión conlleva la simultánea conciencia de sí. Así, tener evidencia "del" ser implica tener conciencia "de" ser; no es lo mismo, pero no se da un acto sin el otro.

La evidencia primera del ser como acto de ser del cual todo ente participa, constituye un "saber originario" por el que es posible todo juicio posterior; se trata de una presencia implícita en la mente de todo hombre, pero sólo el filósofo se ocupa de hacerla explícita en un fugaz acto de contemplación inicial. Este acto primero, saber originario, contemplación inicial y a la vez conocimiento de sí o autoconciencia, por sí mismo, revela la naturaleza espiritual del alma del hombre. Esta simultánea conciencia del ser y de sí mismo, conlleva la evidencia inmediata de la propia "corporalidad". Así el hombre es la unidad plena de cuerpo y alma. (Idem.:16) Santo Tomás (2001: I pars, q. 84, a. 1, sol.) señala que el acto del entendimiento percibe lo material según su propia 
naturaleza, es decir, que el alma conoce lo corporal por el entendimiento, comprendiendo así su propia corporalidad. El espíritu vivifica y espiritualiza al cuerpo, y el cuerpo es la manifestación y signo de la actividad del espíritu. Es decir, es la unión sustancial de alma y cuerpo representada por la unidad del hombre. Sin tomar en cuenta este origen de la contemplación de la unidad corporal y espiritual del hombre, la educación se convierte en in-educación y destrucción del hombre.

Siendo la "memoria" la presencia actual de determinado contenido a la mente que lo mira como objeto, y que en este caso se trata del acto primero, el espíritu del hombre constituye la memoria originaria. A su vez, como es lo primero aprehendido por el espíritu, se trata de la "inteligencia" como capacidad de ver lo que "es". Luego entonces, el espíritu es memoria y es inteligencia; además el ser presente y trascendente y al ente en cuanto tal, deseado, es querido, lo cual evidencia que el espíritu aparte de memoria e inteligencia, es también "voluntad". Así, el espíritu es memoria, inteligencia y voluntad originarias. Lo anterior supone que el alma espiritual es el principio remoto de las potencias, y las potencias, los principios próximos de las operaciones. (Caturelli, 1982: 18) Por lo tanto, para hablar de educación integral del hombre, es necesario el desarrollo del cuerpo y del espíritu, de sus potencias de la memoria, de la inteligencia y de la voluntad. Si se desarrolla una sola de ellas o una sola de ellas no es desarrollada, se generará una especie de monstruo que es lo contrario a la armónica totalidad del hombre creado por Dios. 
Esta unidad en la que consiste el hombre, ontológicamente es incomunicable, pero a la vez es el fundamento de toda comunicación existencial, moral y psicológica. Además de hacer salir aquello que es el hombre, es decir, lo que ontológicamente es el hombre, la educación le hace crecer con la adquisición y perfeccionamiento de las virtudes gracias a esa comunicación fundamental antedicha.

Resulta imprescindible, la inclusión del perfeccionamiento de la voluntad que se va a dar de acuerdo a la verdad presentada al entendimiento, la cual es captada como buena y digna de ser apetecida.

Las dos facultades racionales del hombre se encuentran en su alma espiritual que es su forma, y son la inteligencia y la voluntad. Ningún otro ser corpóreo participa de estas facultades.

El objeto de la inteligencia es el ser en toda su amplitud. No existe ningún ser que no pueda ser conocido por el intelecto humano. Mientras que el objeto de conocimiento de los sentidos externos es limitado a las cualidades sensibles, como colores, olores, texturas, sabores, etcétera, el objeto de la inteligencia es ilimitado, tan amplio como es el ser. Implica las esencias o las formas abstraídas de los seres sensibles. (García López, 1986:15) El objeto de la voluntad por su parte es el Bien, así con mayúscula, conocido intelectualmente como el Bien Absoluto, o el Bien ilimitado. "La voluntad es la facultad del apetito racional del hombre que ahora la llaman "aptitudes", "capacidades", "competencias" o "funciones, "... que no son sino palabras nuevas para 
expresar lo mismo de lo que hablaban los antiguos." (García López, 1986:63)

Considero relevante en este momento el comentario de García López (Idem.:63) al respecto de que uno de los puntos de la doctrina clásica que "... la Psicología y la Antropología modernas... han visto con más antipatía..., es el de la existencia en nosotros de unas 'facultades' 0 potencias operativas, que, interpuestas entre la sustancia humana y las operaciones que ésta realiza, vinieran a ser los principios próximos de tales operaciones." La tendencia relativista de la educación actual, ha llevado a la necesidad de escudriñar en la Filosofía de la Educación para no quedar sólo en interpretaciones psicologistas sin tomar en cuenta la integridad dualista espíritu-cuerpo de la persona humana.

Santo Tomás de Aquino (2001: I pars, q. 77, a. 1) por su parte, afirma que "... la potencia no es la esencia del alma... porque, como la potencia y el acto dividen el ser y cualquier género de ser, es necesario que tanto la potencia como el acto estén referidos al mismo género... Pues el alma esencialmente, está en el acto... a lo que está en potencia con respecto a otro acto, el estarlo no le compete por su esencia, esto es, en cuanto forma, sino en cuanto potencia... la misma alma, en cuanto subyace a su potencia, es llamada acto primero ordenada al acto segundo. Pero el ser dotado de alma no siempre está llevando a cabo acciones vitales. Por eso, en la definición de alma se dice que es acto del cuerpo que tiene vida en potencia, $y$, sin embargo, dicha potencia no excluye el alma. Por tanto, hay que concluir que la esencia del alma 
no es su potencia, ya que nada está en potencia con respecto a un acto en cuanto que es acto."

García López (1986:66) en las facultades humanas del conocimiento incluye tanto los sentidos externos como los internos y el entendimiento o razón. Asimismo en las facultades afectivas o de "tendencia" considera al apetito concupiscible, al irascible y a la voluntad. Lo anterior es fundamental a fin de identificar cómo y a través de qué aprende la persona humana, para lograr el objetivo propuesto en este trabajo, que es reconocer a la persona humana de manera integral como el fundamento para una educación integral.

Como la potencia y el acto del mismo género, deben estar en la misma línea, si un acto no está en el género de la sustancia, la potencia correspondiente a él tampoco lo estará. Sólo en Dios la operación es su sustancia, no así las operaciones de nuestra alma que no están en el género de la sustancia. (Tomás de Aquino, 2001: I pars, q. 77, a. 1)Se trata de un caso particular de la distinción entre sustancia y accidentes. (García López, 1986:64)

Debido a la diversidad de las operaciones que el hombre realiza, es necesario admitir las facultades o potencias operativas del mismo. El conocimiento a través de los sentidos, como dije, es distinto del conocimiento intelectual, así como las tendencias inferiores, son diferentes de las tendencias superiores que implican libertad. La variedad de operaciones requiere de diversos principios para obrar, así como diversas y específicas capacidades: éstas, son las facultades. El hombre es el principio radical y último; sus capacidades a través de sus 
sentidos internos y externos, así como su inteligencia y el perfeccionamiento de su voluntad se identifican como los principios próximos de operación, (García López, 1986:65) principios que deben ser cultivados por medio de la educación.

\section{Conclusiones}

Tomar en cuenta a la persona humana de una manera integral y desde una perspectiva antropológica y metafísica, a fin de proporcionarle una educación con el mismo adjetivo, requiere de un estudio profundo y ontológico de la misma.

Las reflexiones aquí presentadas se proponen como un punto de partida para el análisis de los planes de acción para las reformas educativas de los diversos niveles, formuladas por las instituciones oficiales. El discurso de los valores, competencias, habilidades cognitivas, comportamentales, operativas, actitudinales, etcétera, tienen sentido en la medida en la que se tenga un concepto claro y profundo de la persona humana.

\section{Fuentes de Consulta}

- AQUINO, Santo Tomás de (2001) Suma Teológica, Madrid: Biblioteca de Autores Cristianos.

- ARISTÓTELES (1944) Tratado del alma, traducción de A. Ennis, Buenos Aires-México: Espasa-Calpe. 
- CATURELLI, Alberto (1982) Reflexiones para una filosofía cristiana de la educación, Dirección general de publicaciones, Argentina: Universidad Nacional de Córdoba.

- GARCÍA Alonso, Luz (2000) El hombre: su conocimiento y libertad, México: Porrúa.

- GARCÍA López, Jesús (1986) El sistema de las virtudes humanas, México: Ed. Minos.

- JOLIVET, Régis (1984) Diccionario de filosofía, Buenos Aires: Círculo de Lectores.

- OCAMPO Ponce, Manuel (2002) Las dimensiones del hombre. Un estudio sobre la persona humana a la luz del pensamiento filosófico de Santo Tomás de Aquino, España: Edicep. 